\title{
Design and Development of New Application for Mobile Tracking
}

\author{
Dr. Shaveta Bhatia \\ Manav Rachna International University, Faculty of Computer Applications, Faridabad, India \\ E-mail: Shaveta26@gmail.com
}

\begin{abstract}
The steady rise of mobile computing devices and local-area wireless networks has fostered a growing interest in location-aware systems and services. Consequently, the location based services has now become one of the most exiting features of the next generation wireless systems. This paper presents the work related to both person oriented and device oriented location based services, where the focus is not only to find the location of person but also to find the location of object (mobile phone).This work is valuable to a user to find the location in cases of kidnapping, loss of phone, security of girl child, location of elder members of the family having weak memory. Also, this type of work is also considered as an active location based service where the user is aware of being tracked with the agreement.
\end{abstract}

Index Terms-MicroAddress Recorder, Location based Services, GPS, Google Maps, and Geocoding.

\section{INTRODUCTION}

Location Based Services (LBS) provide services to the mobile users by explore the location depending on the geographical coordinates for their valuable needs. The mobile phones which are equipped with new technologies and supported by the presence and development of broadband mobile data networks have created a new opportunities for the processing of location based applications. The services based on the information about the indoor and outdoor location of a user or device taking the current position of user in account during the performance of the task is called location based services. These services provide valuable information to the user with the combination of mobile computing and location tracking.

Location is essential to the people to relate themselves and to organize their wordly affairs. These days, mobile phones are affordable to every person. The smart phones in the area of mobile communication devices have become technologically very advance and provide multiple features such as Facebook, Voice Conversation, Viber, WhatsApp, internet facility, Global Positioning System (GPS) etc. For example, if a child is out of home and in trouble, one can search his child and go to that place immediately using the application running on the child mobile phone. Thus the location detection of a child is valuable to the parent at that particular time. Also, to get the travel path for reaching some new place is very valuable to the user. Retrieving information about restaurants and cafes along the path is also important. Moreover, knowing the geographical location of a person at any time adds a new powerful dimension to information services. The main focus of our work is to provide a new interface for location tracking with microaddressing where user can track locations in micro (concise) areas . The distance of the tracked locations from the defined nearby locations is retrieved within $1 \mathrm{~m}$ of radius. The time threshold value has been found $<=1$ minute. The proper record of past locations with date and time of a tracked person is also recorded.To achieve the above mentioned objectives, we have developed a new application called "MicroAddress Recorder" for location tracking of mobile phones with higher accuracy by installing the application on users mobile phone. The aim of this paper is to present a design and implementation of the said application with the development tools used for the application and results given by the application.

\section{RELATED WORK}

This section review the existing work done on location based services carried out by various authors.

Philippe Bonnifait et al [21] developed a Vehicle Autonoumous System for the navigation of vehicles based on Geographical Information System (GIS) technology. This application works by taking the map of roads to localize the space of roads in different areas. Through this technology, the location of vehicle can be determined, which is helpful to drivers and pilots to avoid any accident.

Martijn Pannevis [14] contributed a system called "Nulaz System" to get the location based information for general audience. The system tells about user's current location with the information about good restaurants and good movies going on nearby that location. The application is useful for young persons for entertainment when they are getting bored at home.

Todd Simcock [25] contributed a Tourist Guide application for the outdoor environment. This application work in interest of a user based on their location such as, to find nearest place of attractions, buildings, nearby monuments etc.The application is simple in which easy interface is provided to the user but it works only in outdoors.

Delight Circle [30] is a location-based application 
which is designed for business marketing related to brands This system helps the users to do their shopping from local retailers in an easy and convenient way using their mobile phones and also through internet if user can not afford smartphones.Through this application, a user can get all the latest offers, discounts without moving to a particular place.

I-Surround [4] is a location based messaging platform that provides users with context-aware services that allow them to communicate with each other and to obtain relevant information based on their current locations. This system allows the users to communicate with each other through their mobile devices, smartphones and personal computers. Also the users can get the reminders time to time through messages that contain the information about updated locations using google maps.

Lin Leo et al [12] introduced a system called Markov model, where the positions of various users are recorded in a particular area with the transport modes they are using. The raw data is collected through global positioning system and the use of sensors.

YunZhou Zhang et al [31] contributed a Robot Positioning and their navigation with the help of sensors using cricket node. The centroid algorithm is used to check the accuracy of positioning which contain errors due to signal problems in sensors.

Roy Want et al [22] contributed the novel system called Active Badge Location System in 1992 for the people working in the offices with the help of infrared sensors using trilateration technique. The system works by designing a tag in the form of badges weared by the members of office. These badges emit a signals and a unique code after each 15 seconds. These signals provide the information about their location to the centralized service. The limitation of the system is that, there is a signaling problem in the badges, therefore there is need of batteries for increase the signals of batteries which results into higher costs of the system.

Mathhias Kracht [15] on his work describes the first GPS pilot project for transportation. This project was developed at Dutch Transport Research Centre. The main work of this project is to focus on all travel modes by using active GPS equipment outside the car. With this technology it is possible to monitor individuals at different transportation modes.

Alison Brown et al [1] detailed about GPS based low power wristwatch tracking device called Geozigbee Sensor, developed in 2009 by NAVSYS Corporation under the contract of US Army. This watch is actually a sensor that works on client server approach,where the watch is a client who sends the location information to the server through wireless protocols. The server receive and collect the data and used it for navigational purposes and the user can see the results through web portal.

Haluk et al [9] developed a Wireless Position Detector (WiPod) System which is purely a software based location tracking and determination application. It describes a $\mathrm{K}$ nearest neighbor and triangulation algorithms to estimate the position of mobile user. The algorithms are based on the received signal strength information from access points. The general philosophy in these approaches is to establish a one-one correspondence between a given position and the received signal strength from atleast three transmitters with known locations. This system is basically a wireless positioning system for locating and tracking users inside a building.

F.Aloul et al [6] developed an application for location tracking in 2009 to search friends and colleagues within a campus. This application is implemented by integrating the GPS with GSM Technologies and Google Earth in order to provide the real time data related to user position and location. The implementation of the system is easy and cost effective which helps the users to track college friends and colleagues within campus environment. The friends are provided with Bluetooth and WI-FI facility in their campus for the connectivity of mobile phones. This application is used only in outer space but has limitations for inner space.

Nisarg Kothari et al [19] contributed a methodology for Indoor localization using commercial smart phones comprising dead reckoning and WI-FI signal strength fingerprinting to reliably track their own location. The system works by combination of WI-FI with accelerometers, magnetometers and gyroscopes for fast and accurate estimation for localization. The system has a drawback that the performance of WI-FI is restricted by extended database.

Jai Kumar M. Patel and Rahila Patel [10] developed an application to identify user groups based on places visited by a user, date of visiting, longitude and latitude of their place. This information can be used by applications for detection of users and user context. The system is implemented using global system for mobile communication, global positioning system and various clustering algorithms. But the limitation of system is that it only works for group of users and not work for individuals.

S.Almasri et al [23] presented a Zone based Algorithm for developing an efficient location based services system to provide services for end users in a real time by satisfying their needs and considering the processing, bandwidth allocation and connection link performance with GPS positioning accuracy. The System consists of global positioning system and geographical Information system connected through a wireless connection.

After survey of the above cited work, the author concluded that these studies lacks in terms microaddressing, indoor positioning, distance updation, record of previous locations and addition of new areas. This motivated the author to develop new application for location tracking with higher accuracy which is presented in the paper. 


\section{MICROADDRESS RECORDER FOR LOCATION TRACKING OF MOBILE}

The said new application is easy, portable, free and of high quality for tracking a person and to find a lost mobile phone by just installing an application on mobile. The application is capable of delivering the geographical information to the user with the place with semantic meaning. The person having a mobile is tracked at various concise areas. For example, if a person is in an University, the application provides us the output about the building in which the person is present. Further, if the longitude and latitude of a particular room is retrieved through application, then it can also specify the room where the person is at that time. This concise data is recorded, stored and displayed on a map at the administrator site. The satellite provides the coordinates of the mobile client . These coordinates are processed and with reverse geocoding activity and the coordinates are converted into a specific location. The matched locations are then shown on the map. The Android Location API and Google API are the service providers used in the application in order to retrieve and display the locations on the map. The Android Location API [2] provides a powerful and high level framework to automate the tasks such as location provider service. Google Map API [7] is used for embedding the google map images on web page or on mobiles to show the tracked locations. The process of the application is shown through flow diagram in fig. 1 .

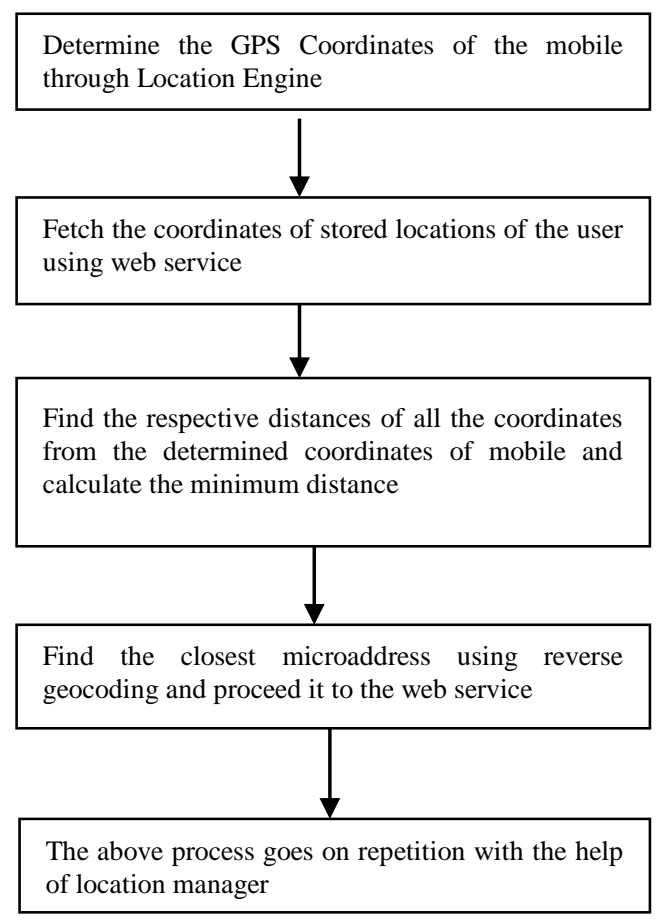

Fig.1. Process of the application

In the current application, the locations of different users can be tracked by just installing the small application "MicroAddress Recorder" on user's mobile. The application executing on the user's mobile phone run continuously without any user interaction with the help of background service available in android phones. For this purpose, an intent is created using a method called onCreate() which is registered in Androidmanifest.xml file of android.The android system will filter the intent stored and then activates it onCreate() method. Now the intent is send to Broadcast Reciever and its OnTimer() function will be activated. Now the system will come in intent state and intent service will start that will continuously call the main function of Microaddress Recorder. The intent method onCreate () contains timer that will send the longitude and latitude of the application after every hour or after a number of hours set in the timer function. The flow diagram of the process running in the background is shown in Fig. 2.

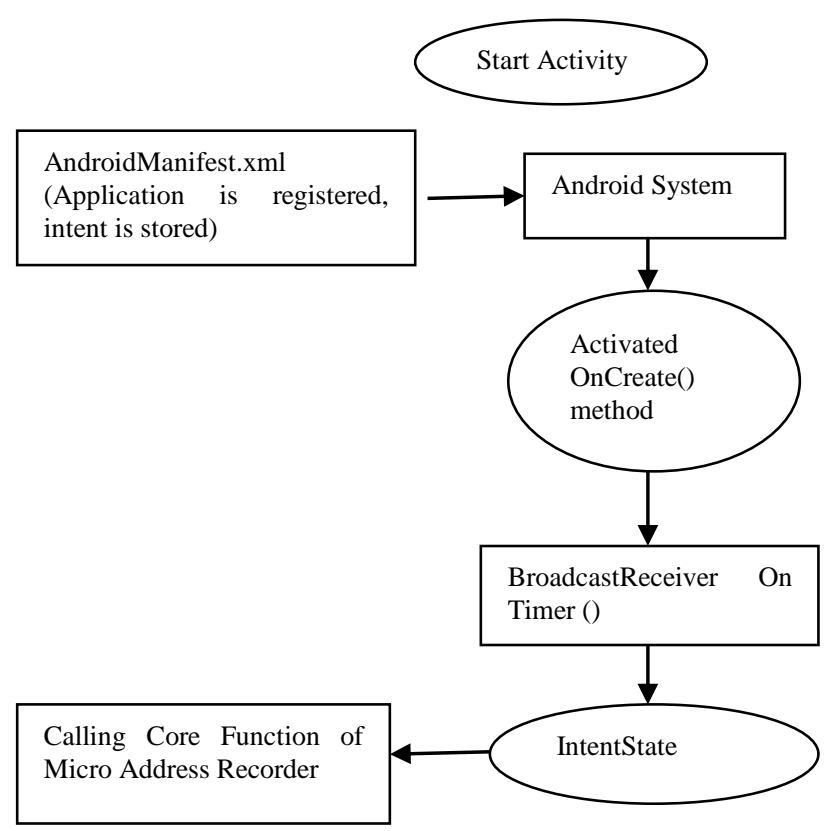

Fig.2. Process running in background

\section{DEVElopMENT TOOLS}

The development tools used for the application must have good accuracy of user tracked location, capacity to work in micro areas, fast speed and easy to understand. The tools used in development of applications are as follows:-

\section{A. Android Development SDK and Android Mobile Phone Operating System}

An Android Operating System is basically an operating system as well as software platform which is based on Linux operating System with Kernel 2.6 and developed by Open Handset Alliance Group [16].Most of the android applications are written in Java. But there is no Java Virtual Machine in its platform and therefore Java byte code is not executed[26]. The Android Java Classes are compiled into Dalvik executables and run on Dalvik which is a specialized virtual machine designed 
specifically for Android[28].The Android Software development kit helps developers to make new applications by writing codes in the Java using Java libraries and J2ME which is provided by third-party applications like Skyshook Wireless XPS System,SoftGPS,PlaceEngine, Navizon or Polaris Wireless etc[3].The features of Android Operating System are Messaging,Browser,Voice Based Featues,Multitask,Screen Capture,Multitouch and Tethering. Android supports the connectivity with various technologies like GSM/EDGE, WIFI, Bluetooth, CDMA, UMTS and LTE. Google released the Android code as open-source under the Apache License [24]. Android supports Application Programming Interfaces (API).The Android Location API is one of the components of android development kit which tells about the execution of function to perform a particular task.

\section{B. Eclipse Development Platform}

The Eclipse Development Platform is the foundation for constructing and running integrated end-to-end software development tools and consists of open source software components that tool vendors use to construct solutions that plug in to integrated software workbenches [27]. The Eclipse Rich client platform is a subset of Eclipse platform that allows users to build applications for their software development. Jface and Workbench provides the user interface with the options of insertion, saving and editing of data. The other components help to add graphics and easy interface provided to user.

\section{Global Positioning System(GPS)}

The use of satellites for finding the position has a good advantage in the area of weather forecast, land surveying and satellite navigation but involves high cost of satellites management. The accuracy of the positioning depends upon the receiving of lesser or higher number of satellites by the user. Therefore, positioning in the buildings are generally incorrect. The most important example of a satellite navigation system in today's world is the Global Positioning System (GPS). As of 2010, the United States NAVSATAR Global Positioning System is only fully operational GNSS as GPS is a Satellite based Navigation system made up of networks of 24 satellites placed into orbit by US Department of Defense [29][5].

\section{Assisted-Global Positioning System(A-GPS)}

Today cell phones are equipped with A-GPS that helps to provide the accurate position of the mobile user.

To provide faster access AGPS acquires and store the information of the user through cellular network rather than the satellite.AGPS uses Proximity to cellular towers to calculate location when GPS signals are unavailable[13]. AGPS is not a real time service provider like GPS here the network usage is always required when a person moves out of service area. It needs only one BTS rather than three BTS to find the position of the device.

\section{E. MySQL Database}

MySQL is an Open Source Database System named after Co-founder Monty Widenius's daughter and supported by Oracle Corporation [18]. MySQL is a database management system (a structured collection of data). These databases are relational that stores data in separate tables rather than putting data in one storeroom. The SQL is the most common standardized language used to access databases. As the name suggests, it is possible for anyone to use and modify MySQL Server which is fast, reliable, scalable, and easy to use and can run comfortably with user applications and web servers.

\section{F. Mobile Services}

To implement Location Based Services from the technology providers to online service providers, content providers, wireless networks, infrastructure providers and content providers, there is a need of standards so that the technologies and devices can work efficiently with each other. The main standards to set up location based services are International Standard Organization (ISO) and Open Geospatial Consortium (OGC) where ISO is a worldwide foundation of national standard bodies.ISO 19119[17] provides general service framework which is used to implement the rules for spatial data service type. It contains the service identified number, called metadata element number for various services which contains the dictionary of geographical services metadata.ISO 19101[20] provides the geographical features that has implicit/explicit reference to location relative to earth.

The open location services provide the framework of open service platform. The combination of all services is called GeoMobilty Server. It acts as application server and answers all core services request. The Service request to mobility server can be send through mobile user and Internet users. The core services defined by Open Geospatial Consortium are Directory Service, Presentation Services, Gateway Services, Location Utility Services and Route Service [11]. The directory service provides the subscriber to access the online directory to find nearest places and services. For example: where is nearest haldiram's restaurant, where is nearest railway station and so on. A Gateway Service act as an interface and useful for giving request for current location.

The Location Utility Services are used to determine the geographical position when place name or street address or postal code is known. The responsibility of Presentation Services is to display the geographic information on the mobile. It allows obtaining the map of specific area. Route Service is used to specify the route of the user.

\section{TESTING OF MICROADDRESS RECORDER}

The extensive testing has been carried out around the city of Faridabad to check the efficiency and accuracy of MicroAddress Recorder. The application is tested on 
Samsung Galaxy Trend Duos GT-S7562 smartphone. The application is tested in Manav Rachna International University Campus on a particular date at different blocks .The updating of location with date and time while person is moving in that campus is shown in table 1. From table 1 below, it is summarized that threshold value of particular time frame $<=1$ minute. The location is displayed on the map with distance as shown in figure 3 using google maps. The location with distance time are continuously updating while the person is moving is shown in figure 4 where history of tracked locations of a person is stored. The change of distance is within radius of 1 meter available at administrator site. Further, the application works in both indoor and outdoor.

Table 1. Results of the application

\begin{tabular}{|c|c|c|c|}
\hline Latitude & Longitude & Place & Date Time \\
\hline 28.4508221 & 77.2836337 & $\begin{array}{c}\text { A Block,IInd } \\
\text { Floor } \\
\end{array}$ & $\begin{array}{c}\text { 22/06/15 8:32 } \\
\text { a.m }\end{array}$ \\
\hline 28.4507713 & 77.2834442 & $\begin{array}{c}\text { A Block, } \\
\text { Ground Floor }\end{array}$ & $\begin{array}{c}22 / 06 / 158: 28 \\
\text { a.m }\end{array}$ \\
\hline 28.4505465 & 77.2831648 & $\begin{array}{l}\text { A Block, } \\
\text { Parking }\end{array}$ & $\begin{array}{c}22 / 06 / 158: 26 \\
\text { a.m }\end{array}$ \\
\hline 28.4508258 & 77.2837065 & $\begin{array}{l}\text { A Block, First } \\
\text { Floor }\end{array}$ & $\begin{array}{l}22 / 06 / 15 \\
8: 30 \text { a.m }\end{array}$ \\
\hline 28.4509703 & 77.2837949 & $\begin{array}{l}\text { Room No. A } \\
\text { 15,A Block }\end{array}$ & $\begin{array}{c}22 / 06 / 158: 37 \\
\text { a.m }\end{array}$ \\
\hline 28.4509147 & 77.2845691 & F Block,MRIU & $\begin{array}{c}\text { 22/06/15 8:48 } \\
\text { a.m }\end{array}$ \\
\hline 28.4505337 & 77.2837894 & $\begin{array}{c}\text { HOD Office, } \\
\text { Third Floor }\end{array}$ & $\begin{array}{c}22 / 06 / 158: 33 \\
\text { a.m }\end{array}$ \\
\hline 28.4508189 & 77.2835479 & $\begin{array}{c}\text { Director Office, } \\
\text { Ground Floor }\end{array}$ & $\begin{array}{c}\text { 22/06/15 8:43 } \\
\text { a.m }\end{array}$ \\
\hline
\end{tabular}

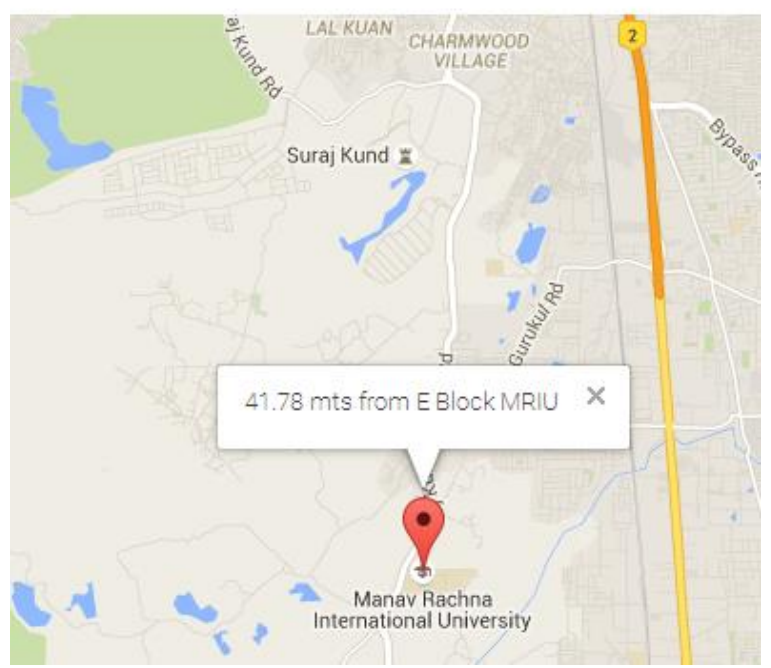

Fig.3. Location tracked with distance is shown using google maps[8].

The application has been tested using correlation and regression algorithms which show the statistical relationship between the actual distances of tracked location from the centralized location set by the author and the distances calculated by the application. We have considered $\mathrm{x}$ as actual distance and $\mathrm{y}$ as the distance calculated by the application. Coefficient of Correlation is calculated using the formulas as shown:

\begin{tabular}{|c|c|c|}
\hline Latitude Longitude & Location & Date Time \\
\hline 28.4509485377 .28373249 & $32.93 \mathrm{mts}$ from Sarita Mam Office & 2015-05-21 23:08:28 \\
\hline 28.4509793477 .28371032 & $32.79 \mathrm{mts}$ from Sarita Mam Office & 2015-05-21 23:08:38 \\
\hline 28.4510332577 .28374757 & $38.9 \mathrm{mts}$ from E Block MRIU & 2015-05-21 23:09:50 \\
\hline 28.4510135377 .28372258 & $36.0 \mathrm{mts}$ from Sarita Mam Office & 2015-05-21 23:09:53 \\
\hline 28.4509613577 .28375537 & $35.57 \mathrm{mts}$ from Sarita Mam Office & 2015-05-21 23:10:02 \\
\hline 28.4509345277 .28376593 & $34.72 \mathrm{mts}$ from E Block MRIU & 2015-05-21 23:10:09 \\
\hline 28.4509142677 .28377659 & 33.58 mts from E Block MRIU & 2015-05-21 23:10:12 \\
\hline 28.4509381677 .28377749 & $33.63 \mathrm{mts}$ from E Block MRIU & 2015-05-21 23:11:00 \\
\hline 28.4509771377 .28378689 & $33.41 \mathrm{mts}$ from E Block MRIU & 2015-05-21 23:11:03 \\
\hline 28.4511076977 .28367882 & $40.54 \mathrm{mts}$ from Sarita Mam Office & 2015-05-21 23:11:25 \\
\hline 28.4511272377 .28367211 & $41.94 \mathrm{mts}$ from Sarita Mam Office & 2015-05-21 23:11:28 \\
\hline $28.45081906 \quad 77.2835485$ & 11.4 mts from Sarita Mam Office & 2015-05-21 23:13:37 \\
\hline 28.4508189877 .28354827 & $11.38 \mathrm{mts}$ from Sarita Mam Office & 2015-05-21 23:13:42 \\
\hline 28.4508189377 .28354789 & $11.34 \mathrm{mts}$ from Sarita Mam Office & 2015-05-21 23:13:45 \\
\hline 28.4508189277 .28354794 & $11.35 \mathrm{mts}$ from Sarita Mam Office & 2015-05-21 23:13:51 \\
\hline 28.4509641977 .28423252 & $12.54 \mathrm{mts}$ from E Block MRIU & 2015-05-21 23:18:04 \\
\hline
\end{tabular}

Fig.4. The details of previously tracked locations with date, time.

Regression of $y$ on $x$

$b_{y x}=\frac{n \sum x y-\sum x \sum y}{n \sum x^{2}-\left(\sum x\right)^{2}}=b_{x y}=0.99$ for our data

Regression of $\mathrm{x}$ on $\mathrm{y}$

$$
b_{x y}=\frac{n \sum x y-\sum x \sum y}{n \sum y^{2}-\left(\sum y\right)^{2}}=b_{x y}=1 \text { for our data }
$$

\section{Coefficient of Correlation}

$$
[\epsilon(x, y)]^{2}=b_{x y} * b_{y x}=0.99
$$

\section{Therefore}

$$
[\epsilon(x, y)]=0.99 \text { upto two decimal places }
$$

As the calculated value of coefficient of correlation using equation 1,2 and 3 is nearby one and positive. Therefore there is higher degree of positive correlation. This implies that the performance of application is highly satisfactory.

\section{CONCLUSION}

The author developed the application called "MicroAddress Recorder" which shows longitude and latitude on the mobile phone. All the information of a 
tracked person is stored in the database which is not visible to the user. The testing result of the application shows that the locations are shown in micro areas. The time threshold value of a moving person is upto one minute. The change of distance of tracked location is within radius of one meter which is shown at administrator site.

The focus of work is to provide a safety platform to locate a child, an elder, a friend and any other known person in both indoor and outdoor and to find lost phone or stolen phone. The same can be extended to include various important applications for the government departments for tracking criminals as per the government rules/norms.

\section{ACKNOWLEDGMENT}

My sincere thanks are due to Dr. Babu Ram, Professor, Manav Rachna International University for his constant guidance and encouragement during the preparation of this paper.

\section{REFERENCES}

[1] Alison Brown et al,"GPS Tracking Location based Service using Wrist Watch Geozigbee Sensors", Proceedings of the 2007 National Technical Meeting of the Institute of Navigation ,Jan 22-24,2007,pp 123-132.

[2] Android Developers," Package Android.Location", available http://developer.android.com/reference/android/location/p ackage-summary.html,retrieved on 1 June 2013.

[3] Denis Huber," Background Positioning for Mobile devices-Android vs. iphone", Joint Conference of IEEE Computer \& Communication Societies, 2011.

[4] Dik Lun Lee et al,"When Location-based Services meet Databases", Journal of Mobile Information Systems, Vol 1, issue 2, 2005, pp 81-90.

[5] Embark Information Technology (P) 1td,"About Vehicle Tracking", an article available at http://www.findnsecure.com/vehicle_tracking.html, retrieved on $2^{\text {nd }}$ July 2012.

[6] F.Aloul et al,'Using Mobile phones for Campus Location Tracking", Proceedings of 7th International Conference on Advances in Mobile Computing and Multimedia,ACM,2009,pp 231-235.

[7] Google Developers,"Static Maps API V2 Developer Guide", available at https://developers.google.com/maps/documentation/static maps/,retrieved on 1 May 2013.

[8] Google," Web Mapping", available at http://maps.google.com, retrieved on 4 July, 2012.

[9] Haluk et al,'WiPoD Wireless Positioning System based on 802.11 WLAN Infrastructure", Proceedings of World Academy of Science, Engineering and Technology, Vol 9, Nov 2005, pp 126-130.

[10] Jaikumar M Patil et al," Implementation, Management and Analysis of User Groups of GSM database", International Journal of Engineering Science and Technology, Special issue Feb 2011, pp 50-54.

[11] Katia Polojavri et al," Distributed System Architectures, Standardization, and Web-Service Solutions in Precision Agriculture", Proceedings of Fourth International Conference on Advanced Geographic Information
Systems, Applications, and Services, Jan 30-Feb 4,Spain,2012.

[12] Lin Liao et al,"Learning and Inferring Trans Transportation Routines", Artifical Intelligence, ElSEVIER,Vol 171, 2007,pp 311-331.

[13] Manav Singhal and Anupam Shukla,'Implementation of Location based Services in Android using GPS and Web Services", International Journal of Computer Science issues, Vol 9, issue 1, No.2, 2012,pp 237-242.

[14] Martijn Pannevis,"I'am Bored! Here is Everybody? Location based Systems on Mobile phones", Thesis, Business Information System, University of Amsterdam, 2007.

[15] Matthais Kracht,"Tracking and Interviewing Individuals with GPS and GSM Technology on Mobile Electronic Devices", Proceedings of 7th International Conference on Travel and Survey Methods, Costa Rica, 2004.

[16] Mitesh Kha,"IOS Android OS Seminar Report", Final Report published in Android Charting Component Library, 2012.

[17] Moritz Neun et al,"Techniques for LBS Cryptography", available at http://www.e- cartouche.ch/content_reg /cartouche/LBStech/en/text/LBStech.pdf.

[18] MySQL," The World's Most Popular Open Source Database", available at http://dev.mysql.com/doc/refman/5.0/en/features.html,retri eved on 23rd July 2013.

[19] Nisarg Kothari et al,"Robust Indoor Localization on a Commercial Smartphone", The International Workshop on Cooperative Robots and Sensor Networks, ELSEVIER Procedia Computer Science, Vol 10,2012,pp 1114-1120.

[20] Norwegian Technology Centre, "Geographic Information Reference Model Imagery”, Working Draft Version 1.0, ISO/TS 19101-2, 2002.

[21] Philippe Bonnifait et al ,"Autonomous Navigation in Urban Areas using GIS Managed Information", International Journal of Vehicle Autonomous Systems, Vol 6 ,2008, pp 83-103.

[22] Roy Want et al, "The Active Badge Location System", Journal of ACM Transactions on Information Systems, Vol 10,issue 1,1992,pp 99-102.

[23] S.Almasri et al, "Location based Services Enhancement using Zone based Update Mechanism", In: PGNet Liverpool John Moores $8^{\text {th }}$ Annual Conference, UK 2007.

[24] Saurabh Bhardwaj et al, "Android operating Systems", International Journal of Engineering Technology and Management Research,Vol 1,issue 1,2013,pp 147-150.

[25] Todd Simcock et al, "Developing a Location Based Tourist Guide Application", Proceedings of the Australasian Information Security Workshop, Conference on Australian Computer Society Frontiers", Vol 21, 2003, pp 177-183.

[26] Vikas Dhiman,"Android Operating System Seminar Report", Apeejay College of Engineering, Sohna, retrieved on 2 July 2010.

[27] White Paper, "Eclipse Platform Technical Overview", An Article by International Business Machines Corp 2006.

[28] Wikipedia, "List of Features in Android" available at http://en.wikipedia.org/wiki/List_of_features_in_Android retrieved on 8 Dec 2012.

[29] Wikipedia, "Global Positioning System" available at http://en.wikipedia.org/wiki/Global_positioning_system,re treived on 18 August 2012.

[30] Yashwant Kumar, "Emerge with your Apps at Nasscom Emerge AppFrame", IAMAI available at http://www.nasscom.in/sites/default/files/pipal_tech.pdf. 
[31] Yunzhou et al,'Research of Localization and Tracking Algorithms based on Wireless Sensor Networks "Journal of Informational and Computational Science, Vol 8,issue 4,2011,pp 708-715.

\section{Authors' Profiles}

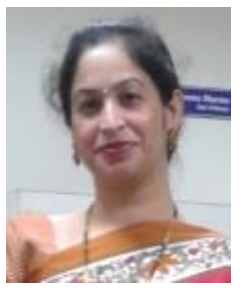

Dr. Shaveta Bhatia is working as an Assistant Professor in Faculty of Computer Applications, Manav Rachna International University, Faridabad for the last 10 years. She had done MCA from Kurukshetra University, Kurukshetra in 2003, MPhil (Computer Science) from Mission Vinayka University, Tamil Nadu in 2009 and $\mathrm{PhD}$ (computer Science) from Manav Rachna International University, Faridabad in 2015. She has 12 years of experience of teaching P.G students and is actively engaged in research work. Her areas of specialization are Mobile Computing, Web Designing, Computer System Architecture, Database Management System and Networking. She has participated in various National and International Conferences and actively involved in various projects. In addition to the academics, she is also involved in the following activities such as Time Table Coordinator, Programme Coordinator, Practical Superintendent and Member of Anti-Ragging Committee.

How to cite this paper: Shaveta Bhatia,"Design and Development of New Application for Mobile Tracking", International Journal of Information Technology and Computer Science(IJITCS), Vol.8, No.11, pp.54-60, 2016. DOI: 10.5815/ijitcs.2016.11.07 